\title{
LOW COST AIS SYSTEM FOR SAFE NAVIGATION
}

\section{NISKOBUDŻETOWY SYSTEM AIS DLA ZAPEWNIENIA BEZPIECZNEJ ŻEGLUGI}

\author{
Maciej Gucma \\ Maritime University of Szczecin \\ Akademia Morska Szczecin \\ Waly Chrobrego $1 / 2$ Szczecin Poland \\ email: macgucma@am.szczecin.pl
}

\begin{abstract}
Automatic Identification System (AIS) ensures automatic transfer of information between sea going vessels and land based monitoring centers. AIS transceivers are obligatory on board vessels of 300 gross register tones and over. System supports safe navigation at confined and open areas, whilst on the former mentioned is especially helpful due to limited range of radar. Article presents low cost AIS system for small vessels and leisure crafts where AIS is not obligatory but might be valuable navigational aid. Some aspects concerning accuracy are presented as well.
\end{abstract}

Keywords: AIS, naviagation, safety

Streszczenie: System AIS (Automatic Identification System) zapewnia automatyczną wyminę informacji pomiędzy jednostkami morskimi oraz lądowymi centrami sterowania ruchem. Odbiorniki systemu są obowiązkowo montowane na jednostkach morskich powyżej 50t brt. System wspomaga proces prowadzenia nawigacji na akwenach otwartych oraz ograniczonych, jednak na tych drugich jest szczególnie przydatny ze względu na ograniczony zasięg radaru. W artykule przedstawiono koncepcję nisko nakładowego systemu AIS przeznaczonego na jednostki nie wyposażone $\mathrm{w}$ taki system, zaprezentowano porównanie takiego systemu z systemem komercyjnym. Aspekty związane z dokładnością rozwiązania także zostały przedstawione.

Slowa kluczowe: AIS, nawigacja, bezpieczeństwo 


\section{LOW COST AIS SYSTEM FOR SAFE NAVIGATION}

\section{Introduction}

AIS is an element in the United Nation's SOLAS convention. It is a shipboard transponder system, operating in the VHF maritime band, that will send ship information to other ships and to shore such as:

- identification (MMSI, Call Sign, Name),

- position,

- heading,

- cargo information,

- other important issues.

Not all vessels are obliged to be equipped with AIS, although ship-owners are aware that this system is extremely valuable navigation aid. This fact and relatively low cost of AIS implementation leads to extraordinary interest in small receivers and class B transponders. Article presents some aspects of using this equipment.

\section{Legal aspects of AIS system implementation}

The system is theoretically capable of handling over 2000 reports per minute and updates as often as every two seconds. The range is typically 20NM (abt. $40 \mathrm{~km}$ ) for ship-to-ship communication and somewhat larger for ship-to-shore communication. The system uses self-organizing time division multiple access (SOTDMA) technology to fulfill the high broadcast rate and to ensure reliable ship to ship operation. AIS is required for the following ships (where applicable date of fulfillment is presented)[7,8]:

- Passenger vessels, of 150 gross tonnage or more, not later than July 1 , 2003;

- Tankers, regardless of tonnage, not later than the first safety survey for safety equipment on or after July 1, 2003;

- Vessels, other than passenger vessels or tankers, of 50,000 gross tonnage or more, not later than July 1, 2004; and

- Vessels, other than passenger vessels or tankers, of 300 gross tonnage or more but less than 50,000 gross tonnage, not later than the first safety survey for safety equipment on or after July 1, 2004, but no later than December 31, 2004. 
IALA (International Association of Maritime Aids to Navigation and Lighthouse Authorities), stated purpose of AIS as: "to improve the maritime safety and efficiency of navigation, safety of life at sea and the protection of the marine environment". IALA presented the first proposal for AIS to IMO in the 1990s. The original motivation for the system was to identify vessels on the radar display. The IALA Technical Clarifications [5] on ITU Recommendation ITU-R M. 1371-1 [9] states: "It was long been realized that an automatic reporting device fitted to a ship would have the potential to increase significantly the safety of navigation and would allow the improved control and monitoring of the maritime events. IMO together with the International Telecommunications Union (ITU) and the International Electrotechnical Commission (IEC) developed a new navigation system called the Automatic Identification System (AIS)"

The requirements for AIS are outlined in Subparagraph 2.4 of Regulation 19 of Chapter V of SOLAS (the International Convention for the Safety of Life at Sea)[7]. The system has been mandatory on all new ships in international traffic since 1 July 2002, (and had been by the end of 2004), include all passenger ships, tankers and other ships of 300 tons in international voyages. Fully implemented in current year (2008), the system will also cover all ships of 500 tons or more in national voyages. The requirements state that [5]: "AIS shall:

1. provide automatically to appropriately equipped shore stations, other ships and aircraft information, Including the ship's identity, type, position, course, speed, navigational status and other safety-related information;

2. receive automatically such information from similarly fitted ships;

3. monitor and track ships; and

4. exchange data with shore-based facilities.

\section{Assumptions AIS transponder operation for modeling purposes}

AIS system consists of one VHF transmitter, two VHF TDMA receivers, VHF DSC receiver, and standard marine communications links complying IEC 61162/NMEA 0183 [6] to shipboard display and sensor systems. Position and timing information is normally obtained from global navigation satellite system (GNSS) receiver. Other information transmitted by the AIS, is electronically obtained from shipboard equipment through electronic links (presented on fig.1).

Transmissions is autonomous and continuous and use $9.6 \mathrm{~kb}$ GMSK( Gaussian Minimum Shif Keying) FM (Frequency modulation) modulation 
over 25 or $12.5 \mathrm{kHz}$ channels using HDLC (High-Level Data Link Control) packet protocols.

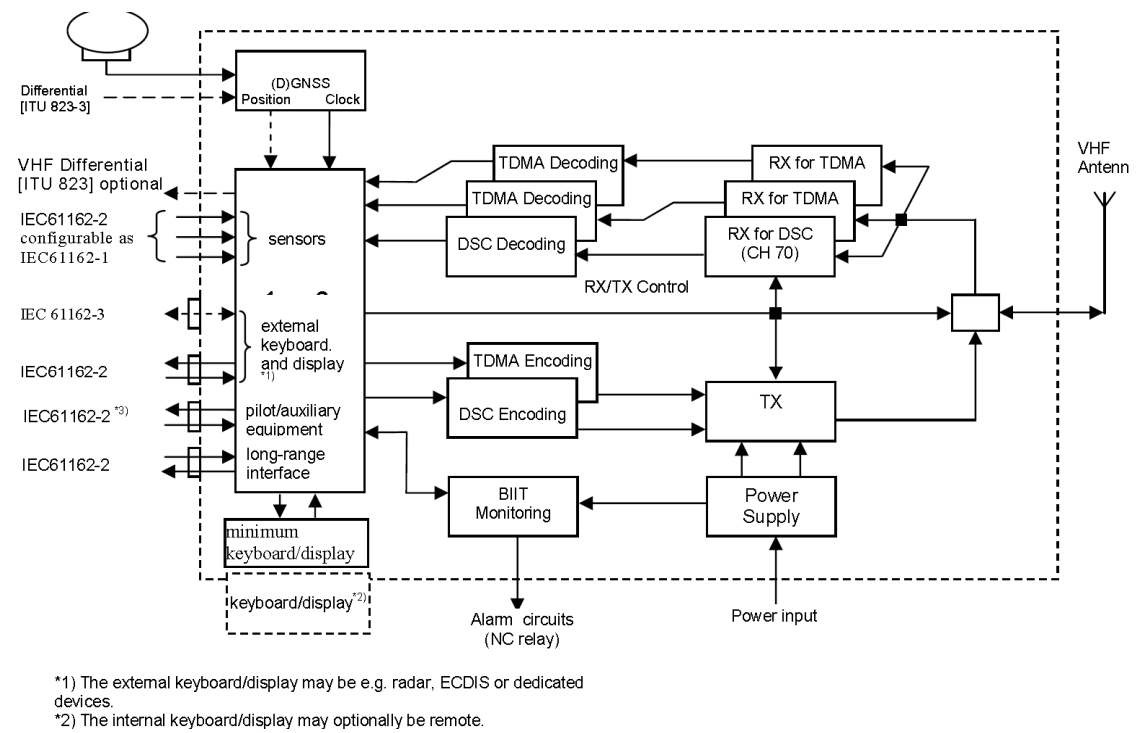

Fig.1 AIS system schematic $[11,10]$

To avoid interference problems, and to allow channels to be shifted without radio link loss, each station transmits and receives on two radio channels and it is: $161.975 \mathrm{MHz}$ - marine channel 87 , and $162.025 \mathrm{MHz}$ marine channel 88. Theoretically, automatic contention resolution between itself and other stations is provided in AIS as well as and communications integrity is maintained even in overload situations $[6,11]$.

A position report from one AIS station (that previously derived one free slot) fits into one of 2250 time slots established every 60 seconds. AIS stations continuously synchronize themselves to each other, to avoid overlap of slot transmissions. Slot selection by an AIS station is randomized within a defined interval, and tagged with a random timeout of between 0 and 8 frames. When a station changes its slot assignment, it pre-announces both the new location and the timeout for that location. In this way new stations, including those stations which suddenly come within radio range close to other vessels, will always be received by those vessels [10].

Type of transmission used in AIS guarantees almost unlimited capacity of targets i.e. ships. When system works with high number of targets the throughput is mainly focused for vessels that are closer to own position (abt. $10 \mathrm{Nm}$ ). Thus the vessels that are in greater distance are not shown and not tracked all the time. 
Niskobudżetowy system AIS dla zapewnienia bezpiecznej żeglugi.

\section{Types of transmissions in AIS}

A Class A AIS unit broadcasts the following information every 2 to 10 seconds while underway, and every 3 minutes while at anchor. The information broadcasted includes[12]:

- MMSI number,

- Navigation status (as defined by the COLREGS "at anchor", "under way using engine", "not under command"),

- Rate of turn - right or left, 0 to 720 degrees per minute,

- Speed over ground - 1/10 knot resolution from 0 to 102 knots,

- Position accuracy - differential GPS or other and an indication if RAIM (Receiver Autonomous Integrity Monitoring) processing is used,

- Longitude - to $1 / 10000$ minute and Latitude - to $1 / 10000$ minute,

- Course over ground - relative to true north to $1 / 10$ th degree,

- True Heading - 0 to 359 degrees derived from gyro input,

- Time stamp - The universal time to nearest second.

In addition, the Class A AIS unit broadcasts the following information every 6 minutes[4, 12]:

- MMSI number,

- IMO number - unique identification,

- Radio call sign - international call sign assigned to vessel,

- Name - Name of ship, 20 characters,

- Type of ship/cargo,

- Dimensions of ship,

- Reference point location (i.e. onboard antenna location),

- Type of position fixing device,

- Draught of ship - 1/10 meter to 25.5 meters,

- Destination - 20 characters,

- Estimated time of Arrival at destination - month, day, hour, and minute in UTC.

Reporting intervals depending on dynamics of ship in AIS are presented in table 1. Whilst exact AIS carrier link description is presented in table

Tab1. Reporting intervals in AIS

\begin{tabular}{|l|c|}
\hline Ship's dynamic conditions & Reporting interval \\
\hline Ship at anchor or moored and not moving faster than 3 knots & $3 \mathrm{~min}$ \\
\hline Ship at anchor or moored and moving faster than 3 knots & $10 \mathrm{~s}$ \\
\hline Ship 0-14 knots & $10 \mathrm{~s}$ \\
\hline Ship 0-14 knots and changing course 31 & $31 / 3 \mathrm{~s}$ \\
\hline Ship 14-23 knots & $6 \mathrm{~s}$ \\
\hline Ship 14-23 knots and changing course & $2 \mathrm{~s}$ \\
\hline Ship $>23$ knots & $2 \mathrm{~s}$ \\
\hline Ship $>23$ knots and changing course & $2 \mathrm{~s}$ \\
\hline
\end{tabular}


Tab. 2.AIS carrier link requirements

\begin{tabular}{|l|l|}
\hline \multicolumn{1}{|c|}{ Parameter } & \multicolumn{1}{c|}{ Characteristics } \\
\hline Frequencies & 161.975 and $162.025 \mathrm{MHz}$ (channels $87 \mathrm{~B}$ and $88 \mathrm{~B})$ \\
\hline Wavelength & $1.85 \mathrm{~m}$ \\
\hline Transmitter power & 2 and $12.5 \mathrm{~W}$ \\
\hline Bandwidth & 12.5 and $25.0 \mathrm{kHz}$ \\
\hline Modulation & Gaussian minimum shift keying (GMSK) \\
\hline Modulation index & 0.25 for $12.5 \mathrm{kHz}$ and 0.5 for $25 \mathrm{kHz}$ \\
\hline Receiver sensitivity & $\begin{array}{l}-107 \mathrm{dBm} \text { for } 25 \mathrm{kHz} \text { and }-98 \mathrm{dBm} \text { for } 12.5 \mathrm{kHz} \\
\text { bandwidth }\end{array}$ \\
\hline Bit rate & 9600 bit/s \\
\hline Synchronization & UTC \\
\hline Message length & $26.7 \mathrm{~ms}(256$ bits) \\
\hline Frame length & 1 min $(2250$ messages) \\
\hline Capacity & 4500 messages/min (for the two AIS channels) \\
\hline Distance delay & 12 bits, equivalent to 202 nm \\
\hline Access schemes & SOTDMA, ITDMA, RATDMA, FATDMA \\
\hline
\end{tabular}

\section{Using AIS onboard non SOLAS vessels.}

There are no restrictions in using AIS receivers onboard non SOLAS compliant vessels like those under 300 BRT tonnes, leisure crafts, tugs and other. Except receivers, this crafts might use AIS class B transponder although it must be licensed one with proper MMSI number (Maritime Mobile Station Identification Number) obtained from ITU. Class B transponder must be fitted with positioning device input (mainly GPS System), and the main disadvantage of this solution is greater cost of class B transceiver than AIS receiver, but self position of such equipped ship is no longer unknown. Comparison of prices (for beginning of 2008 year) for this issue is as follows:

- Class A transceiver costs abt. 7000USD;

- Class B transceiver costs abt. 800 USD;

- Dual channel receiver costs less than 100 USD.

ITU-R Recommendation M.1371-1 describes the following types of AIS:

Class A: Shipborne mobile equipment intended for vessels meeting the requirements of IMO AIS carriage requirement, as described in chapters 2 and 3 of this article.

Class B: Shipborne mobile equipment provides facilities not necessarily in full accord with IMO AIS carriage requirements. The Class B is nearly identical to the Class A, except the Class B[10]: 
- has a reporting rate less than a Class A (e.g. every $30 \mathrm{sec}$. when under 14 knots, as opposed to every $10 \mathrm{sec}$. for Class A)

- does not transmit the vessels IMO number or call sign,

- does not transmit ETA or destination,

- does not transmit navigational status,

- is only required to receive, not transmit, text safety messages,

- is only required to receive, not transmit, application identifiers (binary messages),

- does not transmit rate of turn information,

- does not transmit maximum present static draught.

Class A vessels use SOTDMA (Self Organising Time Division Multiple Access) to send variable length telegrams, short ones on a regular basis, longer ones (static information like cargo, destination, etc.,) less often. Class B vessels using CSTDMA (Carrier Sense Time Division Multiple Access) mainly send fixed length telegrams using time slots not used by Class A vessels. Class A vessels reserve a particular time slot and negotiate the use of that time slot with other Class A vessels within radio range. Class B vessels use any time slot as and when it is available[10]. If no slot is available and a Class B vessel attempts to transmit it simply misses out that, and tries again after a pre-set idle time.

\section{Construction of AIS system}

As described in chapters 2-4 AIS system seems to be very complex and quality demanding structure. Whilst it is more or less so, when transponder class A is taken into consideration, receiver and class B transponder is rather simple and quite inexpensive device. Building AIS receiver there is a need to develop following subsystems:

1) radio RF circuit and detectors for proper frequency,

2) analog audio recovered from RF interface,

3) GMSK demodulator,

4) HDLC/NRZI(Non Return to Zero Inverted) buffer,

5) common digital interface.

Radio RF and detectors could be easily build using existing VHF marine band radio or so called radio scanner with possibility of receiving marine frequencies. Such scanner could be bought for price lower than 100 USD. Other possibility is to build dedicated radio circuit - although fine tuning will be problem than it is in existing radio. For any RF circuit there is a need to collect analog output of unfiltered audio channel. There is huge directory of rebuilding RF's possibilities described in [3]. Interface for analog audio 
is typical for RF applications. At this point analog signal is converted to digital signal (ADC) - and it could be done in computers audio card. After that, all processing is done in specialized software like Shipplotter or AISMon. Such combinations made by author with use of scanner Kenwood TH 28 is presented at fig. 3 .

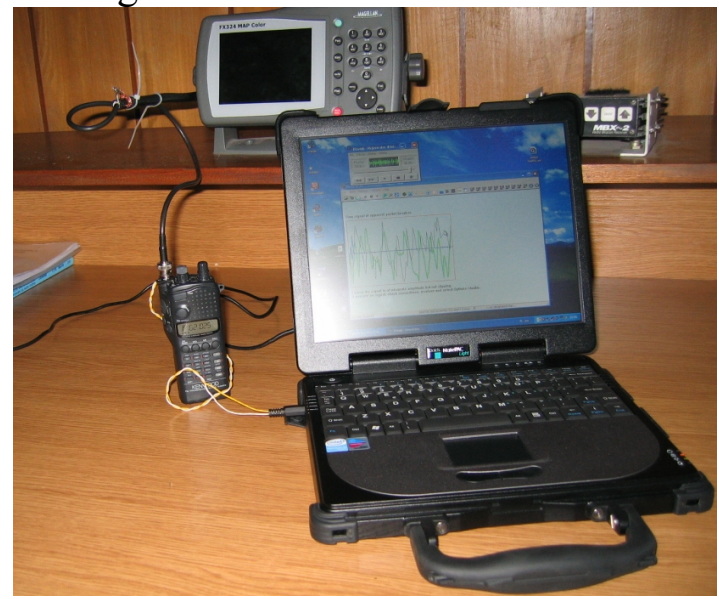

Fig.3 TH28 scanner with application for AIS decoding during tests

Other option is to use dedicated chip like this produced by CML microcircuits CMX7032 that combines in its structure all subsystems from 2 to 5 from list above. Additionally CMX7032 meets the requirements for SOLAS class B transponder [1]. Schematic of this microchip system is presented at fig. 4 .

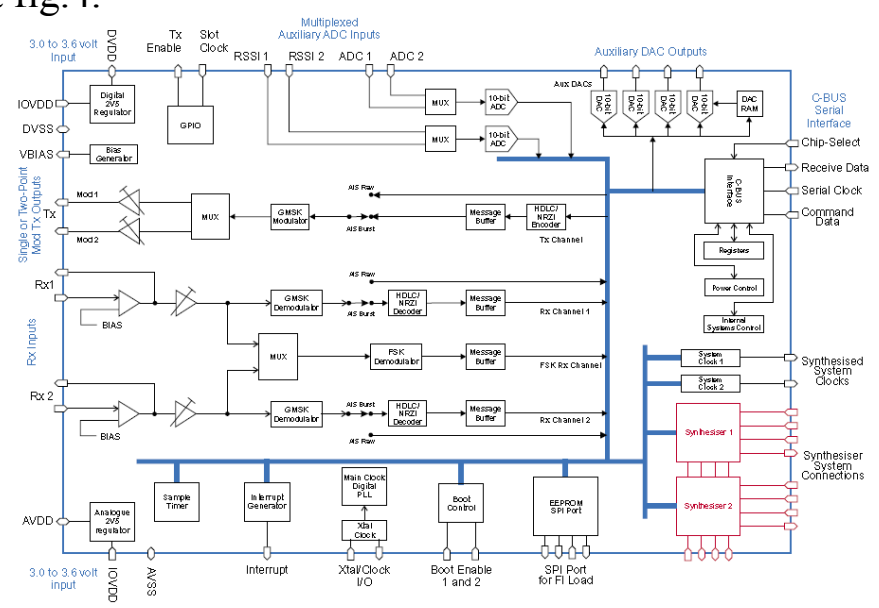

Fig. 4 CMX 7042 microchip schematics [1]

Adding to CMX chip microprocessor and RF part let's build standalone (without computer based software) low cost receiver with class B transponder possibilities. This seems to be a perfect solution for particularly 
any small vessel. Preliminary tests of this chip are quite optimistic and ranges obtained during field surveys are similar to those established by professional receivers. Although full effectiveness of range in real conditions, and comparison to other types of AIS is not yet done. Fig. 5 presents proposed application schematics. Costs of single CMX AIS microcircuit is at level of 50 USD.

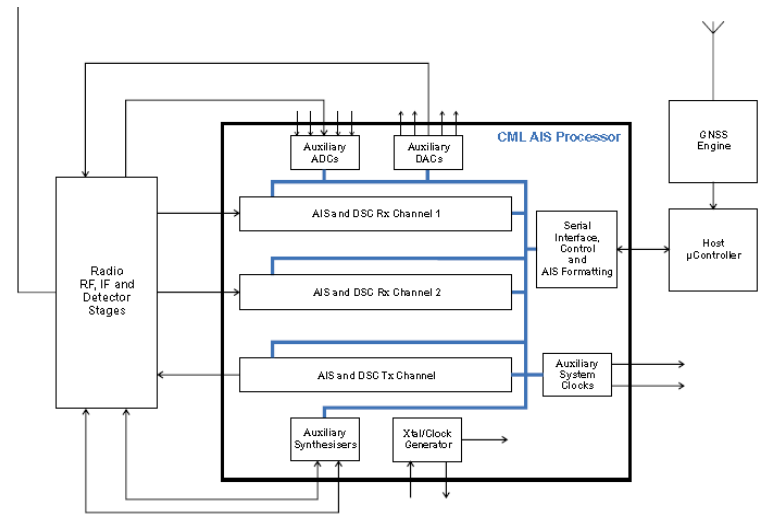

Fig. 5 Application of CML microcircuit.[1]

\section{Simulator of AIS receiver}

Construction of AIS simulator requires programming environment where modeling of radio channel is possible as well as specific type of modulation; i.e. GMSK; is possible. GMSK is subtype of Minimum Shift Keying (MSK) modulation. MSK is a continuous phase frequency shift keying (FSK) binary modulation format. FSK is the digital equivalent to analog frequency modulation (FM). MSK is a form of FSK, with modulation index $h=0.5$. MSK is popular in wireless communications because of its characteristics and desirable characteristics for digital modulation for land and sea mobile radio are[2]:

1) compact output power spectrum;

2) high immunity to noise and interference;

3) ease of implementation.

Minimum Shift Keying (MSK) modulation satisfies the above requirements except for the first one. To make the MSK output power spectrum more compact, the premodulation low pass filter should meet the following conditions[2]:

1) narrow bandwidth,

2) sharp cutoff to suppress high frequency components,

3) small overshoot impulse response to prevent excess deviation of the instantaneous frequency, 
4) preservation of an integrated filter output pulse capable of accommodating a $90^{\circ}$ phase shift to ensure coherent demodulation.

Often a premodulation low pass filter satisfying the above requirements is adopted for Gaussian Minimum Shift Keying (GMSK) modulation, where the data sequence is passed through a Gaussian filter, and the output of the filter is MSK modulated [1]. The width of the Gaussian filter is determined by the bandwidth-time product $\mathrm{BT}$ (e.g., $\mathrm{BT}=0.3$ for $\mathrm{GSM}$ and $\mathrm{BT}=0.5$ for AIS).

MSK is unique due to the relationship between the frequency of a logical zero and one: the difference between the frequency of a logical zero and a logical one is always equal to half the data rate. The modulation index is 0.5 for MSK, and is:

$$
m=\Delta f \times T
$$

where:

$$
\begin{aligned}
& \Delta f=\left|f_{\log i c 1}-f_{\log i c 0}\right| \\
& T=1 / \text { bitrate }
\end{aligned}
$$

For example, a 1200 bit per second baseband MSK data signal could be composed of $1200 \mathrm{~Hz}$ and $1800 \mathrm{~Hz}$ frequencies for a logical one and zero respectively fig. 6 .

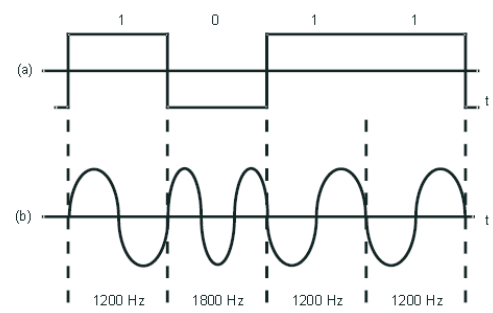

Fig. 6. 1200 baud MSK data. a)NRZ data, b)MSK signal [2]

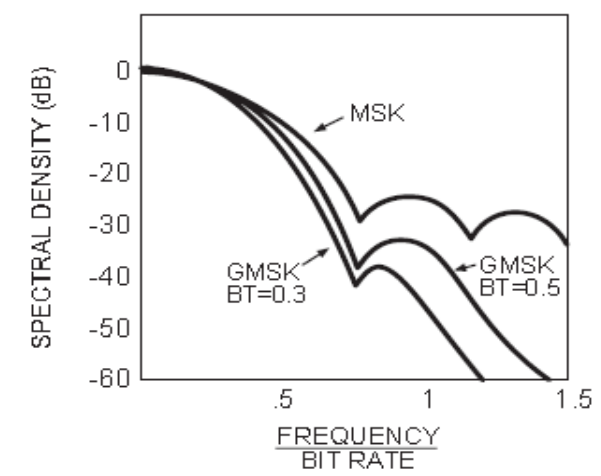

Fig. 7. Spectral density for MSK and GMSK (BT=0.3 and 0.5)[2] 
Niskobudżetowy system AIS dla zapewnienia bezpiecznej żeglugi.

For preliminary tests made by author software simulator, has been developed in Matlab Simulink environment. Following assumptions has been made:

- additive white Gaussian noise channel with SNR ratio of $-44 \mathrm{~dB}$ is used;

- AIS report is treated as random string with Bernoulli distribution;

- power of transmission in single AIS channel is at level of $12.5 \mathrm{~W}$;

- sampling period is $9600 \mathrm{bps}$;

- speed and amount of transmitted data was obtained to simulate a group of 10 vessels;

- simulated vessels are in VHF range of abt. $12 \mathrm{Nm}$;

For such formulated problem three parameters has been registered: Error rate, total number of errors and total number of symbols used in comparison. Screen with simulator block schematic is presented at fig. 8 .

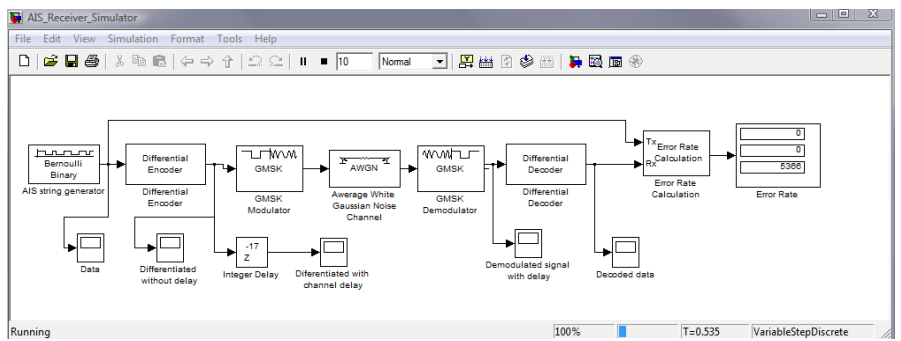

Fig. 8. Blocks in AIS receiver simulator

One of possible application of proposed simulator is assessment of readout errors in low cost AIS system build on basis of CMX 7042 type microcircuits. And assessment made for $\mathrm{BT}=0.3$ and $\mathrm{BT}=0.5$ presents error rate as follows:

\begin{tabular}{|c|c|c|c|}
\hline BT product & Error rate & number of errors & Total symbols compared \\
\hline 0.3 & 0,000750 & 72 & $9,60 \mathrm{E}+04$ \\
\hline 0.5 & 0,000771 & 74 & $9,60 \mathrm{E}+04$ \\
\hline
\end{tabular}

\section{Conclusions}

AIS becomes widely open standard and as far as, it is used properly, it seems to be ultimate tool for safety enhancements, in more and more crowded sea areas. Nowadays it is possible to build AIS receiver using commonly available components like standard VHF radio and typical computer. This option is also used by shippotters (peoples that's are passionate about ships - ship-lovers is often more appropriate name). Detailed technical solutions used for AIS are presented in article. Also following conclusions can be made: 
- it is possible to build low cost AIS receiver or class B transponder,

- such receiver can obtain high integrity level - compared to commercially available ones;

- simulating environment can easily model this low cost receiver.

What concerns next generation of AIS simulator should also include:

- diversity of SNR for different vessels ranges simulation;

- implementation of AIS string formatting;

- more sophisticated error counter;

\section{References}

1) CML Mocrocircuits, Application notes for CMX7042, 2008

2) Collective work, Practical GMSK Data Transmission, MX-Com web based data, 2008

3) discriminator.nl - web based knowledge database

4) EMC Analysis of Universal Automatic Identification and Public Correspondence Systems in the Maritime VHF Band, JSC-PR-04-007

5) IALA Guidelines On The Automatic Identification System (Ais) Volume 1: Part I - Operational Issues, Edition 1.3., Part II - Technical Issues, Edition 1.1.

6) IEC 61993-2 Ed.1, Maritime Navigation And Radiocommunication Requirements - Automatic Identification Systems (Ais) - Part 2: Class A Shipborne Equipment Of The Universal Automatic Identification System (Ais) - Operational And Performance Requirements, Methods Of Test And Required Test Results.

7) IMO Resolution A.917(22), Guidelines For The Onboard Operational Use Of Shipborne Automatic Identification Systems (Ais). IMO Safety of Navigation Circular.227, Guidelines For The Installation Of A Shipborne Automatic Identification System (Ais).

8) IMO Resolution MSC.74(69), Annex 3, Recommendation On Performance Standards For An Universal Shipborne Automatic Identification Systems.

9) ITU-R Recommendation M.1371-3, Technical Characteristics For A Universal Shipborne Automatic Identification System Using Time Division Multiple Access In The Maritime Mobile Band.

10) Navigation Center USCG AIS Information http://www.navcen.uscg.gov/enav/ais/

11) U.S. Submission to the International Telecommunication Union: Document 8B/234-E, Performance Assessment And Interoperability Of Proposed Class B Ais With Existing Class A Ais System Using Simulation Software (2005).

12) U.S. Submission to the International Telecommunication Union: Document 8B/234-E, Performance Assessment And Interoperability Of Proposed Class B Ais With Existing Class A Ais System Using Simulation Software (2005).

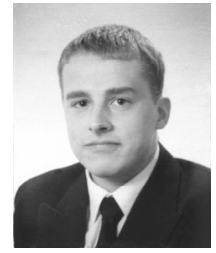

MSc. Eng. Maciej Gucma is researcher in Marine Traffic Engineering Institute of Maritime University of Szczecin, where he conducts his $\mathrm{PhD}$ thesis in field of information optimization for pilot displays onboard vessels. He has a chief mate license for sea going vessels and abt. 3 years of continuous practice onboard. 